\title{
Cultura organizaCiONAL DE CUIDADOS MÉDiCOS, VIOLENCIA INSTITUCIONAL Y DESADHERENCIA AL TRATAMIENTO ANTIRRETROVIRAL DE LAS PERSONAS INDÍGENAS QUE VIVEn CON viH-Sida en Los Altos De Chiapas
}

\author{
Organizational Medical Care Culture, Institutional Violence and Nonadherence to Antiretroviral \\ Therapy of Indigenous People, Living with HIV-AIDS, in the Highlands of Chiapas
}

\section{Rubén Muñoz-Martínez}

Resumen: Los resultados de la investigación que expongo dilucidan algunas problemáticas que la cultura organizacional de cuidados médicos conlleva en el acceso y adherencia al tratamiento antirretroviral de las personas indígenas que viven con VIH-Sida (PVV) en Los Altos de Chiapas. Para ello, desde un eje teórico centrado en la violencia estructural e institucional que opera a través de la discriminación por el origen étnico, la condición socioeconómica y ser portador del VIH-Sida, analizo algunas dificultades con las que se encuentra la PVV indígena que reside en una comunidad al acceder al tratamiento antirretroviral en el Servicio de Atención Integral a personas que viven con VIH de San Cristóbal de Las Casas.

Palabras clave: SIDA, tratamiento antirretroviral, violencia institucional, cultura organizacional de cuidados de salud.

Abstract: The results of the investigation that I expose elucidate some of the barriers, related with the characteristics of a health care organizational culture, for antiretroviral therapy access and adherence of indigenous people living with HIV-AIDS in the Highlands of Chiapas. From a theoretical approach that emphasizes the structural and institutional violence operating through discrimination by ethnicity, socio/economic situation and HIV-AIDS disease, I describe and analyze a case study discussing some of the difficulties that indigenous residing in a community have for the antiretroviral therapy access and adherence in the "Servicio de Atención Integral apersonas que viven con VIH" of San Cristobal de Las Casas.

Keywords: AIDS, adherence to antiretroviral therapy, institutional violence, health care organizational culture.

Rubén Muñoz Martínez. Doctor en antropología social por la Universidad Autónoma de Madrid. Investigador huésped en CIESASSureste. Temas de especialización: antropología médica, salud e interculturalidad, etnopsiquiatría, psiquiatría cultural, mediación intercultural en el ámbito hospitalario y VIH-Sida. Correo electrónico: rubmuma@hotmail.com.
Enviado a dictamen: 10 de diciembre de 2013.

Aprobación: 09 de marzo de 2014.

Revisiones: 1 . 
L os resultados de la investigación que a continuación expongo ${ }^{1}$ muestran algunas de las problemáticas en el acceso y adherencia al tratamiento antirretroviral (TAR) de las personas indígenas que viven con VIH-Sida (PVV) en Los Altos de Chiapas. Para ello, desde un eje analítico relativo a la violencia estructural ${ }^{2}$ e institucional ${ }^{3}$ que opera a través de la discriminación ${ }^{4}$ por el origen étnico, la condición socioeconómica y ser portador del VIHSida, describo y analizo algunas dificultades con las que se encuentra la PVV indígena que reside en una comunidad al momento de acceder al TAR en el Servicio de Atención Integral (SAI) a personas que viven con VIH-Sida de San Cristóbal de Las Casas. ${ }^{5}$ Si bien las problemáticas son multifactoriales, me interesa analizar algunas que corresponden a la cultura institucional de cuidados médicos desde su anclaje en el contexto de residencia del PVV donde se inicia la detección, hasta la llegada al mencionado SAI, esclareciendo su incidencia e implicaciones en la exclusión y desadherencia al TAR. Se presentan las siguientes problemáticas que operan como factores excluyentes: a) detección, derivación y desplazamiento al SAI de San Cristóbal de Las Casas desde las comunidades de residencia de las PVV en Los Altos de Chiapas; b) llegada y acceso a la clínica I, en la que se ubica el SAI, y a la consulta médica de dicho servicio; c) características del SAI y algunas condiciones para el acceso y desarrollo de la consulta desde la diversidad lingüística y cultural: el impacto de la ausencia de traductores/intérpretes lingüísticos y culturales profesionales; $d$ ) derivaciones y centralización de medicamentos antirretrovirales (ARV) y pruebas CD4 y de carga viral: 6 y e) el servicio de reenganche en las comunidades de residencia de la PVV frente a la desadherencia al TAR.

Son muy pocos los estudios que en México han abordado la adherencia ${ }^{7}$ al TAR desde un enfoque cualitativo que incorpore las variables socioculturales y económicas de la relación médico-paciente-institución (Balandrán, Gutiérrez y Romero, 2011). En lo relativo a las personas indígenas que viven con $\mathrm{VIH}$, actualmente son casi inexistentes las investigaciones en esta área, especialmente desde la problemática del estigma de vivir con VIH, y de la violencia institucional que opera directa o estructuralmente por el origen étnico-cultural y socioeconómico. Por ello considero que es importante profundizar en esta línea desde un interés investigativo de tipo teórico y, principalmente, de carácter aplicado.

Para el análisis que aquí llevo a cabo me interesa resaltar el carácter sociocultural de las instituciones, entendidas como sistemas en constante actualización y reordenamiento a través de la práctica profesional de sus actores, la cual está articulada por representaciones, discursos y prácticas hegemónicos que operan estructuralmente por medio de pautas - en términos de Linton (2008 [1942]) - o patrones de conducta sustentadores de las dimensiones simbólicas y materiales sujetas a la normativización y reproductoras de las normas necesarias para la existencia, legitimidad y reproducción de dicho sistema. En este sentido, toda institución es un reflejo de la sociedad y está articulada con los procesos sociales y políticos en los que se inscribe. Como menciona Matsinhe (2007), cualquier institución terapéutica define los patrones institucionalizados de conducta designando las situaciones que se inscriben dentro de estos patrones. Estos patrones son definidos desde una concepción hegemónica del proceso salud/ enfermedad/atención ${ }^{8}$ (en adelante s/e/a) dirigido a una población socioculturalmente dominante, en este caso la biomédica destinada a la población mestiza, urbana, de clase media y media/alta y heterosexual, cuyos representantes son los profesionales de la salud, con trayectorias socioculturales propias inscritas en sus prácticas de cuidados y representaciones sociales, y a los usuarios significados en la consulta como una alteridad o un miembro de dicha población. En un contexto como el que nos ocupa, los recursos materiales, por ejemplo los medicamentos ARV, son producidos y concebidos de forma limitada y su ausencia o desabasto no sólo condiciona, sino que supone una representación y una práctica dominantes en la atención profesional, en una suerte de amenaza cotidiana normalizada; en su distribución opera una selección social ${ }^{9}$ en el nombre de la supervivencia sistémica por medio de la discriminación que suponen las barreras al acceso a los cuidados institucionales 
de salud codificadas en su configuración espacial y organizativa, y en ciertas características de la relación médico/paciente/institución. Esto sucede en función de la divergencia o convergencia del itinerario sociocultural del usuario con la configuración de la cultura organizacional de cuidados y el itinerario de su representante, el médico. Es a través del análisis de la dimensión material y organizativa —existencia de medicamentos, pruebas reactivas, protocolos de actuación, criterios de organización, etcéteraarticulada con la comportamental - representaciones sociales y prácticas de los proveedores de cuidadoscomo podemos dilucidar los fenómenos sociopolíticos inmanentes a los elementos constitutivos de una institución determinada, concebida y reproducida por actores que habitan un contexto histórico y cultural, lo cual nos conduce a revisar el proceso s/e/a desde una dimensión política. Analizo la cultura organizacional ${ }^{10}$ de cuidados del SAI en este sentido.

\section{Panorama epidemiológico del VIH-Sida en Los Altos de Chiapas}

Actualmente, en Chiapas y en la región de Los Altos existe una notable falta de información acerca de los casos de personas que viven con VIH-Sidall y su ubicación. Esto se debe al subregistro producido por la carencia de dispositivos de detección, prevención y atención en las instituciones de salud, así como a un deficiente, cuando no ausente, seguimiento de las personas detectadas por motivos como la migración o el abandono del tratamiento, lo cual se agrava en las poblaciones indígenas (CDI, 2011).

Pese a lo anterior, en los últimos años se ha asistido a un aumento en la cuantificación de casos, a raíz de la intensificación de mecanismos de detección fruto de programas como, por ejemplo, el de detección del cáncer cérvico-uterino (CENSIDA, 2009; 2012a) en ciertos colectivos vulnerables. En México, el segundo país de América Latina con mayor número de personas que viven con VIH (CENSIDA, 2009; 2012b), el acceso universal al TAR tuvo lugar, según datos oficiales, en 2004 (Córdova, Ponce de León y Valdespino, 2009).
No obstante, dicha universalización no parece haber incidido en un descenso de la mortalidad ocasionada por el SIDA, de un 4,3\% por cada cien mil habitantes en 2000 y un 4,36\% en 2011 (CENSIDA, 2013a). Una de las causas que se baraja sobre este fenómeno desde diversos organismos como CENSIDA (2009) es la falta de detección oportuna y de adherencia al TAR.

En términos epidemiológicos, Chiapas se encuentra en el quinto lugar, en el conjunto de México, en cuanto a número de casos de VIH-Sida - 170000 personas que viven con la enfermedad reportadas en 2012 por las instituciones oficiales (CENSIDA, 2013) - , y en cuarto lugar en cuanto al número de defunciones. En este estado, existe un mayor número de hombres que de mujeres que padecen la enfermedad, en la proporción de tres a uno, y es la transmisión sexual la principal modalidad de transmisión reportada. Con los datos estadísticos de los que se dispone en la actualidad para la región, se puede considerar que la epidemia del VIH-Sida se concentra en grupos vulnerables. En esta categoría se encuentran, entre otros, las trabajadoras y trabajadores sexuales, los hombres que tienen sexo con hombres o los migrantes (Infante, Aggleton y Pridmore, 2009; Reartes, 2010; CENSIDA, 2013). El rango de edad en el que se presentan más casos de VIH-Sida es entre 20 y 39 años (CENSIDA, 2012a; 2013). Chiapas es uno de los estados de México con mayor número de población indígena, aunque la etnicidad no se reporta en el tratamiento o la defunción por VIH-Sida, con lo cual no se dispone de datos estadísticos en este sentido (CDI, 2011). ${ }^{12}$

Un dato que evidencia la alta desadherencia de las PVV indígenas al TAR proviene de que, de las 122 personas en Los Altos de Chiapas dadas de alta en el Sistema de Administración Logística y Vigilancia de Antirretrovirales (SALVAR), teniendo en cuenta que éste sólo contabiliza los dos últimos años desde que se creó el programa, 32 personas han abandonado el TAR, las cuales son en su mayoría indígenas -en términos porcentuales un $43 \%$ del total de PVV indígenas, definidas de este modo por hablar una lengua nativa, dadas de alta en dicho sistema ${ }^{13}$ (entrevista al responsable del programa de VIH-Sida en Los Altos, 2012)-. 


\section{Metodología}

El periodo de la presente investigación comprende de marzo de 2010 a diciembre de 2012. Por el carácter de la investigación y las diversas implicaciones potenciales para los actores en ella involucrados no se menciona el nombre real de la clínica estudiada ni de las personas entrevistadas - a excepción de un testimonio que remite a una consideración del contexto mexicano en general- Tampoco se mencionan datos personales que puedan vulnerar la confidencialidad de las fuentes. Se solicitó el consentimiento informado para las entrevistadas y se discutió el uso de las técnicas de investigación con expertos en ética en investigación y antropología médica.

La investigación que se ha llevado a cabo es cualitativa, de tipo etnográfico, y está basada en la teoría fundamentada (Glasser y Strauss, 1967). El interés de la misma reside en su carácter emblemático, esto es, en la posibilidad de llevar a cabo una generalización analítica o tipológica.

Las técnicas de investigación han sido las siguientes:

a. 29 entrevistas en profundidad a los médicos de las consultas y a colaboradores externos y psicólogos vinculados a ellas, así como a los directores de departamento de la clínica I, en la que se ubica el SAI, y de dos clínicas pertenecientes a la Secretaría de Salud y a la sociedad civil, ${ }^{14}$ expertos del ámbito académico y de las asociaciones civiles; jefes de la jurisdicción sanitaria en el Programa de VIH y Tuberculosis; entrevistas a personas que viven con VIH-Sida que acuden al SAI, así como a aquellos que nunca lo hicieron y a los que acudían y dejaron de hacerlo - mestizos e indígenas, ${ }^{15}$ hombres y mujeres, con edades comprendidas entre los $18 \mathrm{y}$ los 45 años- $-\mathrm{y}$ a usuarios simulados.

b. Usuarios simulados: ${ }^{16}$ capacité a ocho usuarios simulados en cuestiones relativas a la discriminación y al estigma hacia las PVV en la atención médica de los profesionales de la salud. ${ }^{17}$ Posteriormente se desarrolló un guión de observación e interacción que produjeron los propios usuarios en función de sus vivencias previas y se realizaron dos grupos focales, uno al comienzo y otro al final de la experiencia. Al concluir cada visita a la clínica contestaron un cuestionario cuyas respuestas fueron contrastadas con los datos de las entrevistas y los grupos focales, y orientaron el curso de las visitas. El perfil de los usuarios fue el de jóvenes, de entre 18 y 30 años, tseltales y tsotsiles — cuatro mujeres y cuatro hombres-.

c. Participación en reuniones y encuentros del personal médico en las clínicas de dos cabeceras municipales de comunidades aledañas a la ciudad de estudio - desde las que se deriva a algunas personas con diagnóstico de VIH-Sida-.

d. Participación en reuniones con asociaciones civiles en Chiapas que trabajan en cuestiones de salud sexual.

e. Visitas a las comunidades de residencia y viviendas de los usuarios que dejaron de acudir a la consulta del SAI y al tratamiento antirretroviral. Por motivos de acceso y tiempo se realizaron mayormente en San Cristóbal de Las Casas y San Juan Chamula.

f. Visitas a la clínica de la cabecera municipal de San Juan Chamula y a dos clínicas en dos parajes del mismo municipio.

g. Conversaciones informales con promotores de salud, personal directivo de hospitales y responsables políticos y administrativos en este campo, así como con familiares de PVV.

\section{Detección y derivación al SAI de San Cristóbal de Las Casas}

En el marco de análisis de la cultura organizacional de los cuidados médicos institucionales, se manifiestan varias problemáticas relacionadas con la detección de las PVV residentes en comunidades indígenas de Los Altos de Chiapas. Si bien las comunidades tienen características sociodemográficas y territoriales diversas, por ejemplo la variabilidad de las distancias hacia San Cristóbal de Las Casas, me remitiré a algunas 
problemáticas relacionadas con las especificidades estructurales de los cuidados institucionales de salud y a las variables que inciden en la exclusión de las PVV de la atención para el control del VIH-Sida.

Como se ha mencionado anteriormente, existe un subregistro notable de casos de VIH-Sida en la región, con implicaciones en la credibilidad de las estadísticas oficiales actuales. En este sentido, desde el punto de vista de la detección de casos, uno de los problemas constatados es que muy a menudo, cuando una persona todavía no detectada o detectada en otros estados acude ${ }^{18}$ a las clínicas de las cabeceras municipales y de los parajes con una sintomatología que podría ser susceptible de una prueba de detección del VIH-Sida, en muy escasas ocasiones ésta se lleva a cabo. Son varios los factores observados que explican este hecho. En primer lugar, la falta de conocimiento sobre el VIH-Sida, así como la falta de sensibilización por parte de los facultativos sobre las problemáticas sociales que influyen en su existencia y sobre los perfiles de vulnerabilidad de ciertas personas y colectivos. En segundo lugar, influyen las representaciones sociales que éstos tienen sobre la sexualidad de los indígenas, entre quienes consideran que no existe diversidad sexual ni vulnerabilidad asociada a las prácticas sexuales por motivo de orientación sexual (Ponce, 2011; Muñoz, en prensa). En tercer lugar, la discriminación hacia las personas portadoras de esta enfermedad, ${ }^{19}$ tal y como he podido observar en el trabajo de campo y en testimonios, al evitarse todo contacto con ellas, incide en su seguimiento y derivación para la prueba confirmatoria y el inicio del TAR. Los tres factores mencionados se articulan, como mecanismos operadores, en la selección social sistémica que decide sobre el destino vital de los cuerpos en función de sus itinerarios socioculturales, perfiles poblacionales y orientaciones sexuales (Muñoz, en prensa), con la ausencia de reactivos para las pruebas de detección en muchos consultorios y su suministro selectivo a los destinatarios priorizados en los programas oficiales - por ejemplo, las mujeres embarazadas, donde hay control y se incentiva la realización de la prueba-.
Cuando una persona es detectada como portadora del VIH-Sida, mayoritariamente a través de programas de la Secretaría de Salud, como es el caso de la detección en mujeres embarazadas, se remite a la clínica I del SAI en donde se le realizará la prueba confirmatoria o Western Blot para, de ser positiva, dar comienzo al TAR. A la luz de los resultados de la investigación, una de las principales problemáticas, articulada con lo mencionado anteriormente, es el hecho de que tanto el TAR como las pruebas CD4 y de carga viral están centralizados. En el primer caso, en el SAI de San Cristóbal de Las Casas y, en el segundo, en el CAPASIT de Tuxtla Gutiérrez. Veremos a continuación algunas implicaciones.

\section{Tratando de llegar al SAI de San Cristóbal de Las Casas desde la comunidad de residencia}

En el caso de las PVV que residen en comunidades indígenas, uno de los principales problemas al momento de acudir a las consultas y de acceder a la medicación antirretroviral estriba en no contar con los recursos económicos suficientes para trasladarse al SAI de la clínica I, ubicada en San Cristóbal de Las Casas. Algunos usuarios deben realizar viajes de más de cinco horas, se quedan a dormir en el albergue habilitado en la clínica para tal efecto, y el coste del viaje y la comida, teniendo en cuenta que a menudo viajan varios integrantes de la familia, puede rondar los quinientos pesos. En otros casos gastan entre treinta y cuarenta pesos cuando residen en una comunidad cercana; sin embargo, como le sucedía a un entrevistado, sus recursos materiales son tan escasos que no disponen de esta cantidad. La imposibilidad de asumir estos importes les obliga a pedir dinero prestado, en ocasiones de forma comprometedora para su anonimato, a familiares o al propio personal de salud. No suelen solicitar el préstamo por medio de las autoridades de la comunidad o del Sistema Nacional para el Desarrollo Integral de la Familia (SNDIF), ya que temen ser visibilizados como portadores del VIH-Sida y sufrir discriminación y represalias en sus comunidades de residencia. 


\section{Ya en la ciudad. Algunas condiciones de entrada a la clínica Iy al SAI}

El SAI de la clínica I pertenece al segundo nivel ${ }^{20}$ y centraliza la atención de control, por medio del TAR, y el seguimiento de los hombres y mujeres que viven con VIH-Sida. Atienden a su vez otras ITS en la jurisdicción número cinco de Chiapas, la cual abarca dieciocho municipios entre los que se incluye San Cristóbal de Las Casas. ${ }^{21}$ El SAI está constituido por una consulta médica externa en la que se proporciona el TAR y una consulta de psicología. Su horario es de lunes a viernes de 16:00 a 20:00 h. El médico del SAI tiene formación como médico general. Sus competencias en infectología las ha adquirido por medio de la experiencia y las capacitaciones que ha cursado a lo largo de los años.22 Desde hace más de diez años trabaja solo en la consulta. En este sentido, no cuenta con personal de enfermería ni ayudante, más allá de una médica voluntaria que lo apoyó durante unos meses en 2011. ${ }^{23}$

La consulta del SAI se encuentra ubicada en un hospital, la clínica I, cuya atención está destinada, a excepción de esta consulta, exclusivamente a mujeres - ginecología- y a niños - pediatría- La mayor parte de los usuarios acuden al SAI derivados de otros servicios de salud, en este caso con una prueba diagnóstica de VIH-Sida positiva previa, para realizarse la prueba de confirmación, Western Blot, y comenzar el TAR. ${ }^{24}$ Pocos son los que se dirigen por su cuenta para demandar información o hacerse pruebas diagnósticas. ${ }^{25}$

En la puerta de entrada a la clínica Ihay un policía, sentado en una mesa, que pide una identificación y un motivo para acceder al recinto por interlocución oral. En este sentido, he constatado en testimonios de personas afectadas y por el propio policía que en ocasiones se niega la entrada a los usuarios varones que no saben -o no quieren- explicar a qué consulta se dirigen. Si no se dispone de una identificación, como les sucede a algunos usuarios, también ven comprometido su acceso, por lo que deben, en el mejor de los casos, negociarlo con explicaciones precisas sobre sus motivos de entrada. En el caso particular de las PVV, y teniendo en cuenta el estigma asociado a su enfermedad, este punto es problemático.
Para las PVV derivadas de otros servicios de salud y para los pocos que acuden por su propia cuenta, el requisito de entrada a la consulta del SAI, además de ser beneficiarios del seguro popular, es hablar español o tener un acompañante que pueda traducir. La obligatoriedad de la presencia del acompañante/ traductor, al no existir intérpretes profesionales ${ }^{26}$ en el SAI, condiciona la asistencia a la consulta del usuario dado que éste dependerá del tiempo y la disposición de su acompañante en todas las ocasiones en las que necesite acudir a la consulta.

Una de las críticas más recurrentes de los usuarios que he podido observar con respecto a la consulta es el tiempo de espera. En ocasiones deben aguardar dos o tres horas, cuando no más, para ser atendidos. Un factor que ralentiza la consulta es la dificultad del médico para ingresar a los pacientes al programa SALVAR, así como para realizar el seguimiento y registro de sus medicamentos, debido al defectuoso o inexistente servicio de internet. La dilatada espera supone un problema notorio para muchos usuarios y sus acompañantes ya que deben pedir permiso para ausentarse de su trabajo y, con frecuencia, lo solicitan por un período de tiempo menor, por lo que la demora en el consultorio puede ocasionarles perjuicios en su ámbito laboral. Que la tónica general sea percibir el tiempo de espera como largo e indeterminado no ayuda al apego del usuario a la consulta.

He asistido a discusiones entre la PVV que no habla español y miembros de su familia, relativas a la dificultad de su llegada a la consulta porque el acompañante no pudo acudir a la cita señalada, que se realiza en horario de 16:00 a 20:00 h. Lo mismo sucede en el caso de las pruebas de carga viral y CD4 porque, si bien no es necesario hablar español, algunos usuarios se niegan a acudir sin alguien que les acompañe y que traduzca en caso de necesidad. Por otra parte, la necesidad del acompañante/traductor, además, supone un coste extra en el transporte, muy a menudo difícil de asumir por el usuario. A continuación abordo algunas problemáticas que la ausencia de traductore ${ }^{27}$ profesionales en el SAI conlleva en la relación, de exigencia de monolingüismo en español, entre médico/paciente/institución. 


\section{La ausencia de traductores profesionales:} estrategias y desigualdades

La Ley general de derechos lingüísticos de los pueblos indígenas (2012 [2003]) establece que "todas las lenguas indígenas serán válidas, al igual que el español, para cualquier asunto de carácter público así como para acceder a los servicios, gestión e información pública" (artículo 7), "debiendo garantizarse que las instituciones, dependencias y oficinas públicas cuenten con personal que tenga conocimientos de las lenguas indígenas nacionales requeridas en sus respectivos territorios" (artículo 13). Asimismo, establece la necesidad de "apoyar la formación y acreditación profesional de intérpretes y traductores en lenguas indígenas nacionales y español" (artículo 13), y que "ninguna persona podrá ser sujeto de cualquier tipo de discriminación a causa o en virtud de la lengua que hable" (artículo 8). Como ya se mencionó, el SAI de la clínica I en San Cristóbal de Las Casas no cuenta con un traductor o intérprete profesional, lo cual conlleva problemáticas que comprenden, de partida, una barrera excluyente para quienes no hablan español, lo que les condiciona a llegar acompañados de un traductor, así como las barreras derivadas de las estrategias que, ya en la consulta, el médico y el usuario tienen que desplegar para hacer mínimamente viable el encuentro clínico. En este sentido, la ausencia de dicha figura supone una modalidad de violencia institucional, con un carácter racista, al condicionar la factibilidad de la consulta a la adaptación del usuario al servicio, no sólo cultural sino también lingüística, y lo responsabiliza de su éxito o fracaso.

Los usuarios que no conocen las características idiomáticas de la consulta son advertidos por los profesionales de la salud o administrativos que los canalizan o con los que se encuentran en las instituciones médicas. Un ejemplo de ello es el de dos usuarios simulados que, en el marco de la investigación, acudieron al hospital y preguntaron por la consulta hablando en tsotsil. En ambos casos, una enfermera y un miembro del personal administrativo les preguntaron si hablaban español y, tras su respuesta negativa, se les advirtió que era necesario que acudieran con un acompañante que pudiese traducir ya que la consulta era exclusivamente en español. Cuando un usuario no habla este idioma, en la clínica I los profesionales de la salud que tratan de facilitar su acceso suelen utilizar en consultas, salas de espera o módulos administrativos, el recurso de pedir a alguien que ejerza de intérprete o, como mencioné, promover la estrategia del acompañante. Los traductores informales son elegidos entre los miembros del personal del hospital, médico o no, y entre los usuarios o acompañantes que se encuentren en el lugar. Una usuaria simulada me relató su experiencia, en este sentido, en el exterior de la consulta del SAI:

Cuando llegué con ropa de Chamula y sin hablar español me fue muy pésimo. En la recepción encontré a tres personas. Era en la tarde [15:30 h]. El asunto es que llegué y pregunté en tsotsil si me podían ayudar. Una mujer [enfermera] salió y preguntó "itienes pacientes aquí?" "No, necesito información sobre una enfermedad", y ella decía "no te entiendo nada". Fue cuando tomó a la primera persona a quien encontró como traductor. Era una persona de Tenejapa. Le preguntó "itú hablas tsotsil?" y le contestó que sí, un poco. Estaba por ahí, estaba esperando a su esposa que estaba teniendo un bebé, con su papá y mamá. La enfermera, que estaba en la recepción, le preguntó si podía traducir porque no entendía absolutamente nada. Yo le dije que estaba buscando información sobre el SIDA, que había escuchado algo pero no sabía qué es. Tradujo y la enfermera dijo que entonces teníamos que ver al doctor. Entró [a la consulta del doctor] y [al salir] dijo que no había llegado todavía el doctor. Me dijo: "no te preocupes, yo te voy a dar información". Me llevó en un rincón donde nadie nos escuchara y le dijo al chico, "acompáñame porque no entiendo nada y tú vas a traducir”. Preguntó qué es lo que quería. Le dije que necesito información del SIDA. Me dijo que el SIDA es un virus que se transmite cuando el hombre se acuesta con muchas mujeres que tienen esa enfermedad y después me lo pegan a mí. Le pregunté que cómo podía saber si tengo 
SIDA o el marido tiene SIDA. El chico lo tradujo y la enfermera me preguntó: "ipor qué quieres saber?, ¿a poco tienes SIDA?" Entonces le dije que no sé, que quizás, probablemente, pues mi marido había estado en Estados Unidos y sospecho que puede tenerlo. Entonces dijo que me tenía que hacer una prueba. Yo le pregunté si el SIDA tiene cura. El chico traducía y la enfermera dijo que no tiene cura, que se queda en el cuerpo y sólo se puede hacer para que el virus no crezca. Le pregunté qué es virus y la enfermera no supo qué responder y dijo que me tenía que hacer la prueba [...] La enfermera estaba apurada pues tenía que irse [...] dijeron que la forma de que no se contagie es usando condones. Les pregunté cómo se utilizaban y dónde podía conseguirlos. El traductor hizo todo lo posible por traducir. Decía, traduciendo, que el condón se lo ponen los chicos en el pene, mostraba mucha seguridad. Pero había cosas que no las traducía igual que como las decía la enfermera [...]. Pregunté que si era pagada la prueba y cómo era. El chavo tradujo bien a la enfermera. Dijo ella que no era pagada si lo hacía con el doctor pero debía tener seguro popular [...]. Pregunté que si yo podía pasar con el doctor, pero como no entendía iqué podía yo hacer si no iba nadie conmigo? Entonces la enfermera le dijo al chico que me acompañara a la consulta. El chico dijo que si no salía su esposa estaba bien, pero que si salía no podía. La enfermera me dice: "no puedes pasar al doctor si no tienes traductor, es más, no puedes pasar con él". Fue así que ella me dijo que no. Le pregunté que si no había traductor y dijo que no, "aquí no tenemos de eso". Entonces la enfermera se fue corriendo, dijo que tenía mucha prisa [...] Tras preguntar a otros trabajadores de la salud en la clínica, esta vez en español, cuando me dijeron que esperara al doctor me quedé allí un rato, como veinte minutos. Entonces [tras entrar a la consulta] cuando salí vi al chico [traductor] y le estaba platicando a sus papás lo que habíamos hablado. Incluso pude escuchar un poco la plática. Decía que yo tenía SIDA y que mi marido estaba en Estados Unidos. Entonces entendí que era peligroso (usuaria simulada, 28 años, 2012).
El relato dimensiona varias problemáticas de la ausencia de intérpretes profesionales en el SAI. Por un lado, la insalvable barrera que supone no hablar español aun siendo hablante de la lengua indígena mayoritaria en Chiapas -el tsotsil- (INEGI, 2009); y, por otra parte, las dificultades con las que se encuentra el personal de salud en dichas situaciones, que les obliga a utilizar recursos improvisados para la traducción con consecuencias difíciles de prever. El riesgo de que traduzcan personas no capacitadas para dicha labor estriba, en este caso, en la vulneración del derecho a la confidencialidad y no discriminación por ser portador del VIH-Sida.

La interacción médico/paciente está regulada por una serie de códigos de comportamiento y normas culturalmente definidas a las que se debe atener el usuario desde su entrada a la consulta y hasta su finalización. Estos códigos responden a conductas y papeles que la situación exige. Gran parte de ellos están articulados o producidos en un medio lingüísticoidiomático constituido por información - por ejemplo, en forma de expectativas, requerimientos o demandasque circula a través de la palabra o el silencio, en la geografía de un espacio, un medio comunicativo delimitado por una mesa, la silla del doctor de un lado frente a la puerta, y la del usuario y su acompañante del otro, con una camilla para pruebas exploratorias y análisis a su izquierda. Los actos comunicativos son interpretados de distinta forma en función de lo que se espera del actor, al atribuirle el interlocutor un conocimiento y apropiación de la cultura organizacional de cuidados de la clínica por medio de competencias - por ejemplo, los modelos explicativos del proceso s/e/a operantes-, el idioma dominante o los códigos lingüísticos y los signos extralingüísticos —como la gestualidad - en el universo del discurso y sus condiciones de producción (Kerbrat-Orecchioni, 1980). En lo que aquí interesa, desde el punto de vista de los médicos y sus representaciones con respecto a los usuarios, la relación está mediada por el origen sociocultural del usuario y la performatividad del mismo, sinónimo de dicho conocimiento y apropiación en la arena de la consulta; esto es, al considerarlos como 
actores que reconocen y son reconocidos, con condición de interlocutor válido. Pero es más probable que suceda cuando de partida se comparte, de una u otra manera, un mismo idioma $\mathrm{a}^{28} \mathrm{o}$, en su defecto, existen traductores profesionales o acompañantes que pueden cumplir esta función. En una situación en la que estas condiciones no se dan o son inciertas, los médicos, al momento de transmitir una información en la consulta, sufren una gran presión frente a la percepción de imposibilidad comunicativa. Para gestionar dicha presión apelan a estrategias ya existentes o de nuevo cuño que operan como barreras excluyentes a la consulta y al TAR, articulándose a la cultura organizacional de cuidados como normas tácitas, como en el ejemplo del requisito de entrada al SAI mencionado antes, o formalizadas en un protocolo o documento regulador de las actividades del centro de salud. En el mejor de las casos, desde el punto de vista de la facilitación del acceso a cuidados de los usuarios, cuando en la consulta los médicos no perciben en la interacción lingüística elementos que permitan aclarar si se entiende o no la información, pueden acentuar la búsqueda o producción de signos, por ejemplo códigos gestuales, que apunten a revelar su éxito o fracaso. Un ejemplo de lo mencionado es la apariencia del usuario y su relación con la norma estructurada por las disposiciones que debe adoptar en dicha situación específica. En el caso de una usuaria a la que se le daba información sobre su condición como portadora del VIH-Sida, traducida por su sobrina al tsotsil, la médica voluntaria en el SAI trataba de apoyarse en su apariencia triste o alegre para saber si estaba comprendiendo lo que le decían y si lo compartía o no:

Aproveché entonces para preguntarle si ella creía o entendía sobre esta enfermedad y le dijo a la sobrina que sí, pero le volví a explicar lo que quiere decir el VIH, la relación entre el virus y las defensas del cuerpo, los posibles peligros y, más importante, que si entendía que a pesar de tomar medicamentos se trataba de una enfermedad que no se curaba sino que sólo se podía controlar. La sobrina, al parecer, le tradujo todo esto, pero de todos modos la paciente siguió sonriente y tranquila como antes. Obviamente no era mi intención ponerla triste ni mucho menos, pero al menos ver algún signo de que entendiera lo que implicaba su diagnóstico (entrevista personal, médica voluntaria en la consulta, 2012).

Este relato muestra, entre otras cosas, la incidencia de la variabilidad cultural de los gestos y la interpretación de los mismos, en función de factores como la presión adaptativa experimentada por el médico en una situación en la que no existe un idioma compartido, y la diferencia cultural, significada por un "otro" que por su trayectoria sociocultural parece querer escapar de la "apropiación" del modelo explicativo biomédico de la s/e/a. Asimismo, se observa en el testimonio la dificultad en la traducción informal sin disponer de elementos de control sobre lo que se está traduciendo y su correspondencia con lo emitido. Como veremos a continuación, pueden existir implicaciones al intervenir algún miembro de la familia del usuario en la selección de lo que se traduce y de qué forma se hace.

\section{Modalidades de acompañamiento-traducción y problemas derivados de una traducción realizada por una persona del entorno personal de la PVV}

En un contexto de diversidad cultural y lingüística, como es el de San Cristóbal de Las Casas y sus clínicas públicas dirigidas a población no derechohabiente -el caso de la clínica Iy el SAI-, la ausencia de profesionales que traduzcan entre el español y las lenguas habladas en la región afecta cotidianamente a muchos usuarios y profesionales de la salud. En el caso particular del SAI, dado que la presencia del acompañante-traductor constituye un requisito ineludible para la consulta de las PVV que no hablan español, la lógica de poder que opera en su cultura organizacional de cuidados se sustenta en la violencia institucional, de forma que se discrimina estructural y sistemáticamente por razones étnicolingüísticas. Esta discriminación está naturalizada bajo el principio de subrogación, al delegar en el usuario y en su entorno las estrategias técnicas de gestión lingüística y sus consecuencias en el acceso y el desarrollo de la consulta. Si bien esta situación se da en diversas áreas 
del panorama de cuidados institucionales en México, en el caso del SAI las especificidades del proceso s/e/a, y el estigma y la discriminación subyacentes al VIH, plantean problemas concretos en este sentido. Expondré a continuación algunos de ellos.

En la consulta del SAI he observado dos modalidades de acompañamiento-traducción que distinguiré a efectos analíticos. En primer lugar, el acompañamiento de la compañera o compañero afectivo del usuario solos o con otros componentes de la familia; predomina la situación en la que su presencia es a la vez de usuarios al ser convocados por el médico por la posibilidad de haber adquirido la enfermedad-. En este caso, la traducción la lleva a cabo, generalmente, el miembro de la pareja que habla español. En segundo lugar, el acompañamiento lo efectúan otros familiares, que, en los casos observados, constituyen las redes de apoyo del usuario. Esto sucede por dos razones principales: o bien temen visibilizar su condición como portadores del VIH-Sida a otros miembros de la familia por miedo, entre otras cosas, a ser estigmatizados y rechazados, o fueron repudiados por la familia, de modo que el acompañante es su único apoyo. En alguna ocasión, principalmente en el segundo caso, puede acudir un promotor de salud de la comunidad de residencia del usuario para ejercer de intérprete.

En ambas situaciones hay que resaltar que en el devenir de la consulta media el género del usuario ya que, por una parte, el médico es hombre, con lo que esto implica, según he podido observar en los testimonios, para la confianza de las usuarias -indígenas y mestizas - cuando están solas en la consulta y quieren transmitir información relativa a su intimidad. Y, por otra, destaca el hecho de que la mujer dependa de la traducción del marido ya que el número de mujeres que no hablan español es considerablemente mayor que el de hombres, ${ }^{29}$ especialmente en San Cristóbal de Las Casas $(70,9 \%)$ y algunas comunidades de Los Altos de Chiapas como Zinacantán (67,7\%) (INEGI, 2009). Hay que tener en cuenta la articulación de las relaciones desiguales de género en el campo de la consulta en la dimensión idiomática y lingüística. En el caso de los usuarios indígenas esta variable es percibida por los médicos a través de las representaciones sociales dominantes de sus sociedades y relaciones de pareja: "veo un problema en el caso de las mujeres quienes, incluso entendiendo aquello que se les dice, no tienen autorización para hablar o dar su opinión en presencia del hombre" (entrevista a médico del SAI, 2012).

Cuando se trata de una consulta en la que el usuario parece no hablar español y acude con un acompañante como traductor, se espera del médico que, para preservar la confidencialidad, pregunte al usuario o al acompañante - lo cual, al menos entre los entrevistados, nunca ocurre en el SAI- si este último sabe el motivo de la consulta. Si la respuesta es negativa y si considera que el usuario habla un mínimo de español para la viabilidad del encuentro, puede pedir al acompañante que salga de la consulta. Si en este devenir constata que el usuario no habla español, entonces tiene que optar por dos escenarios: a) abortar la consulta al no cumplir con los requisitos mínimos para su factibilidad, respetando el derecho a la confidencialidad del usuario; b) confiar en la traducción y en las "buenas intenciones" del acompañante al descubrir que se trata de una consulta relativa al VIHSida, desconociendo las consecuencias negativas de la decisión en el entorno personal del usuario. La ausencia de un intérprete profesional impone unas condiciones de partida que para el médico resultan frustrantes y tienen repercusiones de tipo deontológico al implicar un fuerte desgaste emocional por la exigencia de la presión adaptativa a la situación. A ello hay que sumar que el médico se encuentra solo en su desempeño profesional, y no dispone de una mirada externa a su práctica ni de un mecanismo que permita gestionar las situaciones que experimenta cotidianamente, en este caso de complejidad comunicativa.

En el ejercicio profesional de la traducción lingüística en la diada médico-paciente, el traductor introduce juicios y valoraciones relativas al diagnóstico, tratamiento o seguimiento, los cuales, en un marco metodológicamente controlado, no son por necesidad perjudiciales para la operatividad y eficacia de la consulta, sino que favorecen su devenir ${ }^{30}$ (Hsieh, 2007). En el caso del traductor-acompañante, quien carece 
de competencias profesionales para este desempeño y pertenece al entorno personal del usuario, el escenario puede ser otro. En las entrevistas a médicos, PVV y usuarios simulados he constatado que algunos acompañantes-traductores, a su vez posibles usuarios o no, suelen atribuirse el papel protagónico de informantes y lo hacen modificando la información que transmite el médico al usuario y que éste recibe de él, a través de valoraciones sobre el modo de transmisión del VIH y el uso del condón, juicios sobre la moralidad o amoralidad de la conducta del enfermo, o sobre las relaciones de género o el tipo de parejas y de relaciones sexuales que se deben o no tener. En el caso particular de las parejas esto es especialmente problemático al haberse adquirido el VIH, en muchos casos, por una relación extramarital, por la falta de información sobre medidas preventivas o por el ocultamiento deliberado de la enfermedad, que ya se tenía antes de comenzar la relación. He podido constatar que, a efectos de invisibilizar socialmente la enfermedad, a menudo el compañero afectivo o algunos miembros de la familia están involucrados en la decisión de si la mujer va o no a la consulta, dado que están en juego, entre otras cosas, el descrédito del hombre porque en el entorno se supondrá que él fue transmisor o el miedo a la discriminación y expulsión de la familia del seno de la comunidad. El nudo de tensiones que se da en este tipo de situaciones proporciona una pista de la poca fiabilidad que puede tener, en un contexto tan sensible, una traducción sin un mínimo de precauciones metodológicas que garanticen la transmisión efectiva de la información y en la que se controlen los factores que intervienen en la desadherencia del usuario, de modo que la diada médico-paciente no se convierta en una triada cuyos efectos sean poco previsibles y de difícil manejo.

\section{Consejerías e información sobre procedimientos, pruebas y medicamentos}

El protocolo de actuación de la Secretaria de Salud con las personas que demandan una prueba rápida de detección o confirmación -Western Blot - del VIH-Sida obliga a una consejería previa a la prueba así como a otra posterior en el caso de confirmación (CENSIDA, 2010). Para la Elisa o prueba rápida, dichos procedimientos, que pueden ser puestos en práctica por el médico o por el psicólogo, ${ }^{31}$ suelen ser obviados con frecuencia tanto en el SAI, cuando se trata de una asesoría previa a la prueba, como en las clínicas a las que acudió con anterioridad el usuario indígena. La mayoría de las PVV indígenas entrevistadas a las que pregunté si se les facilitaba información sobre otro tipo de pruebas o los medicamentos prescritos, mencionaron que no la recibieron ni en el SAI ni, de ser el caso, en las consultas previas en los centros de salud de sus comunidades de residencia. ${ }^{32}$ No se informa sobre pruebas como análisis de sangre, sobre exploraciones de detección o atención de otras ITS, sobre medicamentos o sobre los propios esquemas del TAR, como sus características y potenciales efectos secundarios, más allá de una explicación general sobre la necesidad de tomarlos siempre y no interrumpir el tratamiento (Muñoz, en prensa). En el caso de las pruebas CD4 y de carga viral manifestaron haber recibido información sólo en el SAI; sin embargo, no la comprendieron, por lo que no sabían contestar a mis preguntas sobre la finalidad de las pruebas, su periodicidad, su relación con el TAR y el control de la enfermedad. ${ }^{33}$ Ninguna PPV entrevistada mencionó ausencia de información con respecto al VIH-Sida en el SAI tras la prueba confirmatoria; sin embargo, tras ser derivadas de sus comunidades de residencia, fue éste el primer lugar donde la obtuvieron y la comprensión de la explicación resultó problemática. Un ejemplo de ello es el siguiente:

En una de las entrevistas que realicé tras una consulta del SAI a un acompañante - sobrino- de una PVV y al promotor de salud de su comunidad de residencia que acababan de ejercer de traductores, este último me comentó que en la comunidad nadie sabía de la enfermedad; sin embargo, él sí la conocía. ${ }^{34}$ Al transcurrir veinte minutos de conversación ambos me empezaron a hacer preguntas sobre la forma de transmisión del VIH-Sida - por ejemplo, si se podía contagiar dando la mano o bebiendo en el mismo vasola eficacia de los antirretrovirales y su precio dado que desconocían si eran o no gratuitos en el SAI. Interpelados 
a su vez por mis preguntas, pues dudaba de si se trataba de una demanda de información de contraste con más fuentes, me contestaron que era la primera vez que los profesionales de la salud les hablaban de ello. Esto me sucedió en varias entrevistas a PVV en sus comunidades de residencia, con situaciones clínicas diversas; sin embargo, en este caso ocurrió después de la consulta de la usuaria con ellos presentes, y de que el médico les proporcionara información sobre el VIH-Sida y el TAR. Se trataba de la primera consulta tras la confirmación del diagnóstico efectuado un año atrás en el propio SAI. ${ }^{35}$

\section{La función del psicólogo y su implicación profesional en el SAI}

El psicólogo en el SAI desempeña diversas funciones profesionales. Entre otras, proporciona las consejerías previas y posteriores a las pruebas de detección, además de brindar orientación, escucha y comprensión a la PVV (CENSIDA, 2006). El psicólogo, por su formación y funciones, puede llegar a explorar aspectos psicosociales de la PVV y su contexto de vida, así como problemas relativos a la discriminación ${ }^{36}$ que inciden en su adherencia al TAR. En este sentido, es fundamental su presencia -durante un periodo de mi investigación de casi medio año no hubo psicólogo en el SAI- y desempeño profesional por tener notables repercusiones en el refuerzo del vínculo de los usuarios con el servicio y la adherencia al tratamiento. Para ello, siguiendo el protocolo, el médico debe canalizar al usuario a la consulta del psicólogo. Si bien el recurso a este profesional no es habitual en el SAI, no he tenido constancia de usuarios de origen indígena derivados a su consulta. Un factor explicativo de esto, por los testimonios recogidos, ${ }^{37}$ remite a que los médicos suponen que este recurso es ineficaz o que los usuarios no están interesados al tener "otro tipo de cultura". Sin embargo, esto no sucede en contextos en los que los usuarios son únicamente indígenas. Un ejemplo es el de la clínica de la cabecera municipal de San Juan Chamula en la cual la psicóloga, que trabaja con el acompañamiento de un traductor-intérprete en la mayoría de las consultas, goza de gran aceptación por parte de los usuarios una vez que se les explica su función (entrevista personal a psicóloga de la clínica de la cabecera de San Juan Chamula, 2012). Otro factor explicativo es que se concibe al psicólogo como una figura indeterminada en sus funciones y al que se recurre para situaciones de urgencia, esto es, cuando el usuario muestra conductas que en opinión de los médicos remiten a un desequilibrio emocional o psicológico notable. La difícil coincidencia o complementariedad de los modelos explicativos del proceso s/e/a - el biomédico y los de la "cultura del paciente" — o eldudoso pluralismo asistencial en la búsqueda de atención del usuario indígena (Muñoz, en prensa), y la variabilidad de las narrativas del padecer, entre otros factores, dificultan o "eximen" al médico de esta labor. Por otra parte, no se promueven actividades como reuniones de seguimiento e intervención con los usuarios entre el médico y el psicólogo o con grupos de autoayuda. Tampoco existen otros espacios de encuentro cotidiano, como talleres sobre prevención secundaria, entendida ésta como estrategia para mejorar la calidad de vida de las PVV. Tampoco hay una implicación de la sociedad civil en el monitoreo y rendición de cuentas del servicio (Muñoz, en prensa). En otras palabras, el usuario está solo en el SAI. En este sentido, la violencia institucional que puede operar, ejercida estructural o directamente contra las personas discriminadas por su origen sociocultural, es difícilmente visibilizada y expuesta a la presión del juicio público para su erradicación.

\section{Características del SAI, medicamentos antirretrovirales y pruebas CD4 y de carga viral. Carencias y centralizaciones}

La centralización del TAR en el SAI de San Cristóbal de Las Casas, y de las pruebas CD4 y de carga viral en el CAPASIT de Tuxtla Gutiérrez, incide notablemente en la dificultad del acceso de las PVV de bajos recursos que no residen en estas ciudades. Por otra parte, el SAI no cuenta con muchos de los servicios de un CAPASIT. ${ }^{38} \mathrm{Un}$ ejemplo de ello es el de la obligada derivación desde el SAI al infectólogo pediatra del CAPASIT de Tuxtla Gutiérrez para que, siguiendo el protocolo, los niños de 0 a 18 años 
puedan comenzar el TAR. ${ }^{39}$ Estas características de la cultura organizacional de cuidados se articulan con las variables mencionadas anteriormente - dificultades económicas para financiar el viaje, ausencia de intérpretes profesionales en el SAI y sus consecuencias en el acceso y desarrollo de la consulta, tiempo de espera para la misma, disponibilidad desigual de los servicios, etcétera-, de modo que se constituyen en condicionantes para la llegada al SAI y la adherencia al TAR de las PVV indígenas que residen en una comunidad, especialmente si ésta se encuentra geográficamente alejada. A ello se suma la incidencia de la falta de antirretrovirales y medicamentos para enfermedades oportunistas, así como los recortes en las pruebas CD4 y de carga viral (Muñoz, en prensa) y el actual desabasto de pruebas rápidas (Alvarado, 2013; De los Santos y Mariscal, 2013). En el caso del desabasto de ARV, algunos usuarios, según me relataron, tuvieron que regresar a sus comunidades sin el tratamiento. Acudir cada mes a la consulta para obtenerlo, según el protocolo, tampoco ayuda a quienes no pueden costearse el viaje. En el caso particular de las pruebas CD4 y de carga viral, los usuarios que viven en comunidades alejadas no siempre pueden acudir a la hora en la que sale el vehículo de la Secretaría de Salud que les lleva sin coste - las siete de la mañana-, ni pueden llegar el día anterior y quedarse a pasar la noche en el albergue. El recorte en los laboratorios del CAPASIT de Tuxtla en el período de estudio condujo a que sólo pudieran acudir cada mes siete usuarios de los veinte que eran enviados con anterioridad para realizarse dichas pruebas. Si la recomendación es que éstas se lleven a cabo cada tres o cuatro meses, los recortes postergan el monitoreo del efecto del TAR y la correlación con la evolución y control de la enfermedad, aumentando las posibilidades de una falla terapéutica. ${ }^{40}$ Ello, en este caso, es un añadido más en la exclusión a una atención eficaz a los usuarios que de por sí no tienen un acceso fácil por las barreras de tipo lingüístico y cultural, así como geográficas y económicas.

Con el objetivo de facilitar el acceso a los medicamentos ARV de los usuarios que viven en comunidades indígenas, e inspirándose en el programa de tuberculosis, el responsable del programa en la jurisdicción impulsó en el segundo semestre de 2012 una propuesta para que, sorteando la centralización defendida por su alto precio y el riesgo de uso fraudulento, puedan obtenerlos en las clínicas de las cabeceras municipales. Comenzó la experiencia piloto en la cabecera municipal de San Juan Chamula. Cabe mencionar que las consultas médicas en las comunidades suelen ser atendidas por médicos pasantes que realizan su servicio social durante un período de tiempo puntual. Tratar con un médico distinto cada vez que la PVV acude a la consulta le genera, según he podido constatar, desconcierto y desconfianza. Si en otro tipo de demandas de atención médica la inexistencia de un facultativo estable es problemática, en el caso de las personas que viven con VIH-Sida la confianza y la percepción del respeto al anonimato resultan cruciales para un buen apego al TAR y a la consulta. El eje de la propuesta es entregar, cada cierto tiempo y a demanda, los ARV a un médico destinado y formado para tal efecto de la clínica de la cabecera municipal con el objetivo de que distribuya a los usuarios que lo necesiten, pero también en otros casos, como en la profilaxis para evitar el contagio por vía perinatal durante el parto.

\section{El servicio de reenganche al TAR. Médicos que viajan a las comunidades}

Cuando se ha detectado a una PVV y no acude a la consulta del SAI, o cuando ya acudía pero deja de hacerlo, el médico y el responsable jurisdiccional del programa de VIH-Sida prestan un servicio de reenganche que consiste en ir a la residencia de la PVV para conocer cuál fue el problema que desembocó en la desadherencia. Por motivos de tiempo y carga de trabajo, según el testimonio del responsable jurisdiccional del programa, no suelen prestar este servicio con la regularidad deseada. ${ }^{41}$ Las distancias, la orografía y el estado de las carreteras no facilitan las visitas ya que en ocasiones deben recorrer más de cuatro horas en el trayecto de ida y vuelta.

Por otra parte, desde la clínica de la cabecera municipal de las comunidades se realizan visitas a las 
casas de estas personas. Las visitas se llevan a cabo como parte del protocolo de reenganche y seguimiento principalmente en los casos de mujeres embarazadasa través de miembros del centro de salud de la cabecera municipal o del jefe de la jurisdicción del programa de VIH-Sida, quien promueve la visita acudiendo al centro de salud de la comunidad. Uno de los problemas derivados del equipo médico que pude observar es la cuestión lingüística, principalmente al momento de hablar, en este caso en tsotsil, con las mujeres que viven con VIH. En ocasiones acompaña al equipo, cuyos integrantes sólo hablan español, una promotora de salud en calidad de traductora. Sin embargo, no es fácil encontrar a una persona que desempeñe esta labor con las precauciones necesarias para garantizar el anonimato del usuario y evitar el riesgo de que la PVV sea discriminada en la comunidad (CDI, 2011). Éste es uno de los miedos principales que suelen tener las PVV. Un ejemplo de ello es el hecho de que en la clínica los traductores, al igual que los promotores de salud —en ocasiones es la misma figura-, son designados por la comunidad.

En las visitas a las casas de las PVV, la forma de acudir cobra relevancia de cara a que el personal de cuidados sea percibido como una ayuda o una amenaza. El uniforme identificatorio como profesionales de la salud, la ambulancia o vehículo oficial y el número de visitantes pueden resultar alarmantes pues el vecindario se plantea preguntas y puede comprometerse el anonimato de la PVV.

Por último, además de lo mencionado sobre el riesgo de discriminación en la comunidad de la $\mathrm{PVV}$, hay que señalar que los representantes de las instituciones son percibidos por algunas personas de colectivos subalterizados, en este caso los pueblos indígenas, como una amenaza. En dos grupos de discusión que organicé con jóvenes tsotsiles y tseltales para coordinar la estrategia de los usuarios simulados, observé, en este sentido, narrativas de imaginarios y experiencias relacionadas con la agresión y la violencia, lo cual incluía el asesinato y la desaparición de indígenas por parte de los profesionales de la salud. ${ }^{42}$ Considero que si la visita se realiza con discreción y con conocimiento y sensibilidad hacia el contexto de vida de la PVV, ésta será muy beneficiosa para su adherencia al TAR y a la consulta médica en la clínica de la comunidad y en el SAI.

\section{Algunas consideraciones finales}

Los resultados de la investigación expuestos exploran algunas problemáticas en el acceso y adherencia al tratamiento antirretroviral de las PVV en Los Altos de Chiapas. Para ello, desde un eje de análisis relativo a la violencia estructural e institucional que opera en la cultura organizacional de cuidados médicos a través de la discriminación por el origen étnico, la condición socioeconómica y ser portador del VIH-Sida, se han explorado algunas dificultades con las que se encuentra la PVV indígena que reside en una comunidad al momento de acceder al TAR, en el Servicio de Atención Integral a personas que viven con VIH-Sida de San Cristóbal de Las Casas. De los aspectos relativos a la cultura organizacional de cuidados médicos analizados desde su anclaje en el contexto de residencia de la PVV donde se inicia la detección, hasta la llegada al mencionado SAI, cabe realizar las siguientes consideraciones: en primer lugar hay que destacar la notable incidencia de la centralización del TAR en el SAI de San Cristóbal de Las Casas, y de las pruebas CD4 y de carga viral en el CAPASIT de Tuxtla Gutiérrez, en la desadherencia al tratamiento de las PVV que residen en comunidades y tienen bajos recursos económicos. Es importante impulsar medidas que, como la mencionada sobre la descentralización de los antirretrovirales, permitan un mayor acceso al TAR de estas personas, para las cuales el coste del transporte es con frecuencia inasumible. La transformación del SAI en CAPASIT optimizaría el acceso a las pruebas CD4 y de carga viral, y proveería al servicio de mayores recursos, entre otros un infectólogo pediatra, lo que evitaría la derivación a Tuxtla Gutiérrez. Ello debe ir acompañado del abasto y mejor distribución, y monitoreo de su factibilidad, de pruebas CD4 y de carga viral, y medicamentos ARV. Otra variable 
que incide en la desadherencia al TAR, y que se inscribe en una modalidad de violencia institucional al discriminar a los usuarios por su trayectoria sociocultural e idioma, es la ausencia de traductores lingüísticos y culturales profesionales en la consulta. Su existencia permitiría la no dependencia de estrategias problemáticas para la adherencia del paciente al TAR, como el traductor-acompañante sin un control metodológico sobre la práctica de la traducción. Considero necesario el monitoreo de las prácticas de los médicos con relación a las derivaciones que efectúan o deberían efectuar a los servicios del SAI, como el de psicología, y a las actuaciones conjuntas, en este caso con el psicólogo, así como de la información al usuario sobre las pruebas a llevar a cabo y el TAR, sus características y sus potenciales efectos secundarios.

En este tenor es importante que otro profesional de la salud apoye al médico en la consulta y que el personal de cuidados del SAI impulse grupos de autoayuda para mejorar el acompañamiento del usuario en su tratamiento con antirretrovirales y las prácticas profesionales del facultativo. Por último, creo que un servicio eficaz de reenganche supondría un importante punto de inflexión en la mejora del, como hemos visto, problemático acceso y adherencia al TAR de las PVV que residen en comunidades. Potenciar el servicio de reenganche por medio de brigadas capacitadas y que involucren a los profesionales del SAI implicaría un paso en la subversión del principio de adaptación unidireccional del usuario a la cultura organizacional de cuidados médicos y sus disposiciones espacialestemporales, con ausencias que, haciendo de la necesidad virtud, se traducen en prácticas que apelan a la escasez de recursos materiales y tiempo y encubren la violencia institucional que sufre esta población. Es decir, es importante que el servicio obligue a que dichos profesionales conozcan los contextos de vida de los usuarios, que sean formados en competencias culturales, género, derechos humanos y diversidad sexual, y que se cuente con personal de apoyo capacitado en estas áreas, así como con traductores e intérpretes lingüísticos y culturales profesionales.

\section{Notas}

${ }^{1}$ La investigación se llevó a cabo en el marco de una estancia postdoctoral en CIESAS-Sureste financiada por la Agencia Española de Cooperación Internacional y Desarrollo del Ministerio de Asuntos Exteriores y de Cooperación español. Agradezco a ambas instituciones la posibilidad de haber llevado a cabo esta investigación. 2 Ver, en el ámbito general, Galtung (1996), y en el particular del VIH-Sida, Farmer (2003).

3 Opera como expresión de la violencia estructural la cual, en algunos casos, adquiere la forma del llamado racismo institucional (Carmichael y Hamilton, 1967; Sibony, 1993; Foucault, 1998[1990]; Wierviorka, 1992).

${ }^{4}$ Me interesa resaltar la discriminación basada en el origen sociocultural (ver autores mencionados en nota 2) y el estigma al vivir con VIH (Goffman, 2006 [1963], en un ámbito general, y Parker y Aggleton, 2002; Comaroff 2007, en el caso del VIH; Infante y Aggleton, 2009, en el contexto mexicano; y Chong et al., 2012, en el particular de Chiapas).

${ }^{5}$ El SAI, como veremos después, centraliza la atención a personas que viven con VIH-Sida en el área de Los Altos de Chiapas.

${ }^{6}$ Las células CD4 -en ocasiones denominadas células-T o células auxiliares - son glóbulos blancos que ayudan a organizar la respuesta del sistema inmunitario frente a las infecciones. El recuento de CD4 es la medición del número de estas células en un milímetro cúbico de sangre - no en todo el organismo- - La carga viral es el término empleado para referirse a la cantidad de VIH en sangre (Carter, 2010).

7 La adherencia será considerada como "el grado en el que el comportamiento de una persona - tomar un medicamento, seguir un régimen alimentario y ejecutar cambios del modo de vida - se corresponde con las recomendaciones acordadas de un prestador de asistencia sanitaria". En este sentido, es necesario tener en cuenta la conformidad del paciente, y su participación activa respecto a las recomendaciones. Aquí me referiré a adherencia o apego indistintamente, a la consulta médica como la afiliación o vínculo que genera el paciente con dichas recomendaciones que 
en ella tienen lugar, especialmente el seguimiento del tratamiento ARV.

${ }^{8}$ Ver discusión sobre el modelo médico hegemónico de Menéndez (1984).

9 Por selección social me refiero a dos cuestiones: a) el juicio de valor, acompañado de prácticas, que el médico emite con respecto a los modos de interacción, comportamentales, y al origen étnico y social del paciente; b) las características de la cultura organizacional de cuidados médicos que filtra a las PVV en función de la situación socioeconómica en la que viven - lo que media en su mayor o menor acceso y en la modalidad del mismo, a la consulta y al tratamiento-.

${ }^{10}$ Para una descripción detallada de dicho concepto ver Peiró (1990) y Schein (1992).

${ }^{11}$ Desde que se registraron los primeros casos en 1986 y hasta el momento se tienen registrados 4864. Sin embargo, cifras extraoficiales revelan que podrían existir más de veinte mil casos de SIDA, mientras que la Secretaría de Salud reconoce menos de cinco mil (Ramírez, 2011).

${ }^{12}$ Para una discusión sobre este fenómeno ver Ponce (2011).

${ }^{13}$ Con respecto al porcentaje de personas con VIH que continúan en tratamiento doce meses después de haber iniciado la terapia ARV, se estableció en 2010, a partir de la Consulta Nacional de Acceso Universal, una meta para México del 90\% en 2015, en 2011 se sitúa en un 87.9\% (Candia, Ortiz y Gómez, 2012). En este caso se observa un índice menor de no abandono de la terapia ARV, un $74 \%$.

${ }^{14}$ En el caso de los médicos: en la clínica I, objeto de estudio, es un hombre de 46 años, originario de San Cristóbal de Las Casas, y una mujer, voluntaria en la consulta y originaria de México Distrito Federal, de 27 años. En la clínica II de la Secretaría de Salud, una mujer de 50 años, originaria de San Cristóbal de Las Casas. En la clínica III, de la sociedad civil, dos médicos, hombre y mujer, de 28 y 31 años. Los psicólogos son cinco mujeres y un hombre. El criterio de selección de las personas entrevistadas se ha ceñido a la obtención de evidencia, relativa al eje de la investigación, por medio de la triangulación y el contraste de los datos empíricos de diversas fuentes.
15 Para preservar el anonimato no mencionaré las comunidades en las que residen las PVV indígenas entrevistados.

${ }^{16}$ La estrategia del usuario simulado, efectuada por los investigadores u otras personas capacitadas para ello, se ha utilizado en ámbitos diversos de la investigación, formación y evaluación de la calidad de servicios, como por ejemplo en salud y en el campo de la investigación periodística (Wallraff (1987) y en ciencias sociales. Ver, en el área de las religiones, Festinger, Riecken y Schacter (1970) o Wallis (1976), a menudo desde una perspectiva crítica con el fin, entre otros, de denunciar delitos o evidenciar situaciones de explotación y abuso ${ }_{17}$ El objetivo de la capacitación fue contrastar la información obtenida a través de ellos. Eran conscientes de posibles factores como el estigma y la discriminación presentes en su demanda de información y atención médica en el SAI.

${ }^{18}$ Y que por motivos diversos no menciona su enfermedad.

19 En los casos observados se conoce previamente la seropositividad de la persona.

${ }^{20}$ Antes de la creación de la clínica I en 2011 era llamada el Hospital General I - fundado a principios de los años setenta- Se encuentra ubicado en el centro de la ciudad. Sus especialidades básicas son ginecobstetricia, cirugía, medicina interna, cuidados y pediatría. Cuenta con treinta camas censadas y con un área de urgencias (Argüello y Freyermuth, 2004, Gobierno del Estado de Chiapas, 2012). El hospital opera las veinticuatro horas del día de lunes a viernes en turnos matutinos, de 7:00 a 15:00 h, y vespertinos, de 14:30 a 22:30 h — con guardias en la noche de los médicos interinos-. El servicio del SAI se creó en el año 2001.

${ }^{21}$ Amatenango del Valle, Aldama, San Juan Cancuc, Chalchihuitán, Chanal, Chamula, Chenalhó, Huixtán, Larráinzar, Mitontic, Oxchuc, Pantelhó, San Cristóbal de las Casas, Santiago el Pinar, Las Rosas, Teopisca, Tenejapa y Zinacantán (Secretaría de Hacienda, 2013)

${ }^{22}$ La especialización de los médicos también es un factor de peso en el éxito del tratamiento (Magis y Barrientos, 2009).

${ }^{23}$ El médico justifica trabajar solo con el argumento de la defensa del anonimato de los pacientes. Sin embargo, 
por lo que he podido detectar, existe una suerte de rechazo por parte del personal de salud para trabajar en este tipo de consultas al temer un riesgo de transmisión ocupacional del VIH-Sida.

24 Muchos usuarios con VIH, son derivados desde diversos municipios de la región de Los Altos y de la Selva Lacandona - Palenque y Ocosingo- al Hospital de Las Culturas debido a patologías asociadas - como tuberculosis- y en estado crítico. Según he podido constatar en entrevistas a expertos, ésta es una de las formas más recurrentes de diagnóstico por las problemáticas en el primer nivel. Tanto en estos casos como en los que acuden directamente a la consulta, el estadio de la enfermedad suele ser avanzado (Entrevista médico SAI, 2011).

${ }^{25}$ Una modalidad de derivación al SAI externa a la red de cuidados pública se produce a través de una asociación civil ubicada en San Cristóbal de las Casas que se dedica a la atención médica a personas indígenas.

${ }^{26}$ Por el término traductores o intérpretes lingüísticos/ culturales profesionales me refiero a un miembro del personal de la clínica que, con una formación en este sentido y remunerado por dicho trabajo, se dedique exclusivamente a la traducción simultánea de la información entre el personal de cuidados y el paciente, así como de documentos escritos, lingüística pero también de tipo cultural.

${ }^{27}$ Los factores que inciden en la desadherencia al TAR relativos a una ausencia de traducción o interpretación cultural, mediación entre modelos explicativos del proceso s/e/a, en la presente investigación se han abordado en otro documento (Muñoz, en prensa).

${ }^{28}$ Desde un punto de vista psico-socio-lingüístico un ejemplo de la variabilidad e implicaciones del uso de un idioma en un contexto clínico de diversidad lingüística es que las personas pueden demostrar diferentes valores y contenidos afectivos dependiendo del idioma que utilicen (Ervin, 1964) o, por ejemplo, recuerdan eventos muy distintos en una u otra lengua (Javier, 1996, en Burck, 2004).

29 Siendo Chiapas la segunda entidad federativa de México con un total de 957255 personas hablantes (INEGI, 2009).
30 Sobre las ventajas y desventajas de la traduccióninterpretación lingüística y cultural, en el caso de los mediadores interculturales en Bélgica y España, he hablado en otro texto (Muñoz, 2013)

${ }^{31}$ En el contexto de la prevención/control del VIH-Sida, se ha definido a la consejería como "el conjunto de actividades realizadas para preparar y confrontar a la persona con relación a sus conocimientos, sus prácticas y conductas con riesgo que lo exponen a la infección del VIH/SIDA" (Magis y Barrientos, 2009).

${ }^{32}$ En ocasiones el usuario no sabe por qué le han enviado al SAI desde la clínica de referencia.

${ }^{33}$ Me llegué a preguntar si la incomprensión tenía que ver con una falta de apropiación por rechazo al modelo explicativo biomédico sobre el control de la enfermedad pero desterré esta hipótesis cuando la PVV mostraba gran interés en dicho modelo explicativo y en ser atendido en el SAI. La entrevista se convirtió en una capacitación, como se verá después.

${ }^{34}$ Interpreté que se presentaba como un promotor de salud competente que acababa de desempeñar un buen trabajo como traductor-acompañante. Por otro lado, cuando se trata de una PVV y de sus acompañantes, sus respuestas críticas al sector salud, enunciadas frente a posibles representantes del mismo, a menudo son paulatinas tratando, en un principio, de no cuestionarlo por miedo a posibles represalias. Con frecuencia yo era considerado por la persona entrevistada como médico.

${ }^{35}$ Esta persona, según fuentes médicas, contrajo el VIH a través de su marido, el cual tuvo relaciones sexuales con otros hombres en el contexto migratorio de destino de San Cristóbalde Las Casas ejerciendoel sexoservicio. Un año antes de la entrevista se detectó la seropositividad del marido en el certificado de defunción, lo cual suele ser muy poco frecuente, según he podido observar. Debido a los antecedentes, se le realizó a la mujer una prueba de detección en su comunidad de residencia y al dar positivo se le derivó al SAI para la confirmación. La usuaria no comenzó con el TAR hasta la fecha de nuestro encuentro, acudiendo al SAI, de nuevo por derivación, tras un cuadro sintomatológico asociado a la enfermedad. 
${ }^{36}$ En un contexto en el que son casi inexistente las quejas formales por discriminación o negligencia médica registradas en el buzón de quejas de la clínica u otros formatos como, por ejemplo, la Comisión Nacional de los Derechos Humanos. Esto tiene que ver, según los testimonios recogidos, con la falta de consideración que los usuarios tienen de sí mismos como sujetos de derecho y por su desconocimiento de dicha posibilidad y de los formatos y características. A su vez, existe miedo a la queja por temor a represalias del personal de cuidados: "Las personas que se atreven a denunciar y a exigir sus derechos son considerados como pacientes conflictivos" (Campos, entrevista personal, 2012).

${ }^{37}$ Testimonios de médicos y psicólogos en Los Altos de Chiapas, pero también en Veracruz donde colaboré con el Grupo Multisectorial en VIH-Sida e ITS del Estado de Veracruz, fundado por Patricia Ponce en 2002.

${ }^{38}$ Para las características de un CAPASI y la historia de la creación de los SAI, ver CENSIDA, 2006.

${ }^{39}$ Con respecto a las particularidades del TAR en esta población, ver Consejo de Salubridad General, 2011.

${ }^{40}$ Para más información sobre la falla terapéutica, ver Vélez et al., 2005.

${ }^{41}$ La frecuencia es irregular. Puede prestarse ninguna, una o dos veces al mes, según observé, en las comunidades más cercanas a San Cristóbal de Las Casas, como Zinacantán o Chamula.

${ }^{42}$ Esta representación ha sido corroborada en discusiones con colegas que desde años atrás trabajan con esta población en Los Altos de Chiapas (en el contexto de Brasil, ver Scheper-Hughes, 1997).

\section{Referencias bibliográficas}

Alvarado, Marco Antonio, (2013) "Dónde están las pruebas para detectar el VIH" en Noticiasnet.mx [en línea], 9 de junio de 2013. Disponible en: http://www. noticiasnet.mx/portal/chiapas/general/169334donde-estan-pruebas-para-detectar-vih-ab [consultado el 6 de octubre de 2013]

Arguello, Hilda y Graciela Freyermuth, (2004) "Servicios de atención gineco-obstétrica hospitalaria: descripción y análisis". Disponible en: http://
sureste.ciesas.edu.mx/Investigacion/Proyectos $\% 20$ especiales/Proyectos/Graciela/Hospitales.pdf [consultado el 23 de enero de 2012].

Balandrán, Dulce Alejandra; Juan Pablo Gutiérrez Reyes y Martín Romero, (2011) “Evaluación de la adherencia antirretroviral en México. Índice de adherencia vs adherencia de cuatro días" en XII Congreso Nacional sobre VIH-SIDA y otras infecciones de transmisión sexual, 26 al 29 de julio, Villahermosa, Tabasco.

Burck, Charlotte, (2004) "Living in several languages: implications for therapy" en Journal of Family Therapy. Núm. 26, pp. 314-339.

Candia Fernández, Elízabeth, Maryori Ortiz Rodríguez y Jaqueline Jomara Gómez Olivas, (2012) Informe de evaluación del Programa de Acción Específico 2007-2012 en respuesta al VIH/Sida e ITS y evaluación de resultados del Proyecto México de lucha contra el Sida, ronda 9 financiado por el Fondo Mundial. México, SALPEL. Disponible en: http://mex-910-g0l-h.funsalud.org. $\mathrm{mx} /$ FondoMundial/Propuesta-2013/DJ1_InformeFinal-VIH-Sida.pdf [consultado ell7 de septiembre de 2012].

Carmichael, Stokely y Charles Hamilton, (1967) Poder negro: la política de liberación en Estados Unidos. México, Siglo XXI.

Carter, Michael, (2010) CD4, carga viral y otras pruebas. Reino Unido, NAM. Disponible en: http://www. aidsmap.com/v634746749810000000/file/1004226/ CD4_viral_load_and_other_tests_Spanish.pdf [consultado el 10 de mayo de 2011].

CDI. Comisión Nacional para el Desarrollo de los Pueblos Indígenas, (2011) Informe final de la consulta sobre VIHSida y pueblos indígenas en áreas fronterizas. México, CDI. Disponible en: www.cdi.gob.mx [consultado el 3 de febrero de 2012].

CENSIDA. Centro Nacional para la Prevención y el Control del VIH/SIDA, (2006) Manual de organización específico del Centro Ambulatorio para la Prevención y Atención del Sida y otras Infecciones de Transmisión Sexual (CAPASITS). México, CENSIDA. Disponible en: http://www.censida.salud.gob.mx/ descargas/man_org_capasits.pdf [consultado el 10 de junio de 2011]. 
CENSIDA. Centro Nacional para la Prevención y el Control del VIH/SIDA, (2009) El VIH/SIDA en México 2009. México, CENSIDA. Disponible en: http://www.censida.salud.gob.mx/descargas/2009/ VIHSIDAenMexico2009.pdf [consultado ell4 de abril de 2011].

CENSIDA. Centro Nacional para la Prevención y el Control del VIH/SIDA, (2012a) Vigilancia epidemiológica de casos de VIH/SIDA en México. Registro nacional de casos de SIDA. Actualización al 30 de junio de 2012 (CENSIDA). México, CENSIDA. Disponible en: http://www.censida.salud.gob.mx/descargas/2012/ sida_vih30junio2012pub2.pdf [consultado el 12 de diciembre de 2012].

CENSIDA. Centro Nacional para la Prevención y el Control del VIH/SIDA, (2012b). VIH/SIDA en México 2012. México, CENSIDA. Disponible en: http:// www.censida.salud.gob.mx/descargas/biblioteca/ VIHSIDA_MEX2012.pdf [consultado el 20 de enero de 2013].

CENSIDA. Centro Nacional para la Prevención y el Control del VIH/SIDA, (2013) Vigilancia epidemiológica de casos de VIH/SIDA en México. Registro nacional de casos de SIDA. Septiembre 2013. México, CENSIDA. Disponible en: http://www.censida.salud.gob.mx/interior/cifras. html [consultado el 5 de noviembre de 2013].

Chong Villarreal, Francisco et al., (2012) "Estrategias de personas con VIH para enfrentar el estigma asociado al VIH-Sida. Pacientes del Hospital General de Huixla, Chiapas" en Estudios Fronterizos. Vol. 13, núm. 25. Enero-junio 2012, pp. 31-55. Disponible en: http://www.uabc.mx/iis/ref/REFvoll3num25/ EFVOL13NUM25-2.pdf [consultado el 15 de marzo de 2013]

Comaroff, Jean, (2007) "Beyond Bare Life: AIDS, (Bio) Politics, and the Neoliberal Order" en Public Culture. Vol. 19, núm. 1, invierno 2007, pp. 197-219;

Consejo de Salubridad General, (2011) Tratamiento antirretroviral del paciente pediátrico con infección por VIH. Guía de práctica clínica. México, IMSS, ISSSTE. Disponible en: http://www.cndh.org.mx/ sites/all/fuentes/documentos/Programas/VIH/ OtrasPublicacionesdeinteresrelacionadosconelVIH/
IMSS/Tratamiento\%20antirretroviral\%20del\%20 paciente $\% 20$ pediatrico $\% 20$ con $\% 20$ VIH.pdf [consultado el 17 de marzo de 2012].

Córdova Villalobos, José Ángel, Samuel Ponce de León Rosales y José Luis Valdespino (eds.), (2009) 25 años de sida en México. Logros, desafíos y retos. México, CENSIDA. Disponible en: http://www.censida. salud.gob.mx/descargas/SIDA25axos-26mar.pdf [consultado el 3 de abril de 2011].

De los Santos, Sandra y Ángeles Mariscal, (2013) "Incrementa en Chiapas riesgo de contagio de VIHSIDA en mujeres" en Chiapas Paralelo [en línea]. 7 de septiembre de 2013. Disponible en: http://www. chiapasparalelo.com/noticias/chiapas/2013/09/ incrementa-en-chiapas-riesgo-de-contagio-de-vihsida-en-mujeres/ [consultado el 6 de octubre de 2013]. Farmer, Paul, (2003) Pathologies of Power. Health, Human Rights and the New War on the Poor. Berkeley, University of California Press.

Festinger, Leon; H. Riecken y S. Schacter, (1970) When Prophecy Fails, a Social and Psychological Study of a Modern Group that Predicted the Destruction of the World. Minneapolis, University of Minnesota.

Foucault, Michel, (1998) Genealogía del racismo. Buenos Aires, Altamira

Galtung, Johan, (1996) Peace by Peaceful Means. Peace and Conflict, Development and Civilization. Londres, Sage.

Glasser, Barney y Anselm Strauss, (1967) The Discovery of Grounded Theory. Chicago, Aldine.

Gobierno del Estado de Chiapas (2012), Boletín 8735 [en línea]. Chiapas, Gobierno del Estado. Disponible en http://www.chiapas.gob.mx/prensa/boletin/fortalecenatencion-para-la-mujer-en-zona-altos [consultado el 23 de enero de 2013].

Goffman, Erving, (2006 [1963]) Estigma, la identidad deteriorada. Buenos Aires, Amorrortu.

Hsieh, Elaine, (2007) "Interpreters as Co-diagnostician: Overlapping Roles and Services Between Providers and Interpreters" en Social Science and Medicine. Núm. 64. Febrero, pp. 924-937.

INEGI. Instituto Nacional de Estadística y Geografía, (2009) Perfil sociodemográfico de la población que habla lengua indígena. México, INEGI. Disponible en: http:// 
www.inegi.org.mx/prod_serv/contenidos/espanol/ bvinegi/productos/censos/poblacion/poblacion_ indigena/leng_indi/PHLI.pdf [consultado el 16 de abril de 2011].

Infante, César; Peter Aggleton y Pat Pridmore, (2009) "Forms and Determinants of Migration and HIV/ AIDS. Related Stigma on the Mexican-Guatemalan Border" en Qualitative Health Research. Vol. 19, núm. 12, pp. 1656-1668.

Kerbrat-Orecchioni, Catherine, (1980) L'Énonciation. De la Subjectivité dans le Langage. París, Armand Colin.

Ley general de derechos lingüísticos de los pueblos indígenas, (2012 [2003]). México, Congreso General de los Estados Unidos Mexicanos. Disponible en: http://www.sep.gob.mx/work/models/sepl/ Resource/5f08lc03-5ef8-415b-aldf-35b660088c24/ ley_general_derechos_linguisticos.htm [consultado el 26 de agosto de 2012].

Linton, Ralph, (2008 [1942]) El estudio del hombre. México, Fondo de Cultura Económica.

Magis Rodríguez, Carlos y Hermelinda Barrientos Bárcenas (eds.), (2009) VIH/SIDA y salud pública. Manual para personal de salud. México, Centro Nacional para la Prevención y el Control del VIH/SIDA, Instituto Nacional de Salud Pública y Secretaría de Salud. Disponible en: http://www.censida.salud.gob. $\mathrm{mx} /$ descargas/biblioteca/manualvihsidaysaludpub. pdf [consultado el 6 de junio de 2011].

Matsinhe, Cristiano, (2007) "Acceso a los servicios de salud sexual y reproductiva en Mozambique: un análisis de la cultura organizacional y los obstáculos institucionales" en Álvarez Degregori, María Cristina et al. (coords.) Mujer, SIDA y acceso a la salud en África Subsahariana: enfoque desde las ciencias sociales. Barcelona, Medicus Mundi Catalunya. Disponible en http:// www.sidafrica.net/publicaciones/LibroVitaWeb.pdf [consultado el 23 de mayo de 2011].

Menéndez, Eduardo L., (1984) Hacia una práctica médica alternativa. Hegemonía y autoatención (gestión) en salud. México, CIESAS.

Muñoz Martínez, Rubén, (2013) "Mediación intercultural frente a la desigualdad en el acceso y disfrute a la atención sanitaria. Algunas propuestas y problemáticas de sus praxis en Bélgica y España" en Migraciones. Núm. 33, pp. 97-125.

Muñoz Martínez, Rubén, (en prensa) "Atención médica, adherencia al tratamiento antirretroviral y discriminación. Algunas problemáticas en la atención a personas que viven con VIH/SIDA desde una perspectiva antropológica" en Pueblos y Fronteras.

Parker, Richard y Peter Aggleton, (2002) HIV/AIDSRelated Stigma and Discrimination: A Conceptual Framework and an Agenda for Action. Washington, Population Council.

Peiró, José María, (1990) Organizaciones: nuevas perspectivas psicosociológicas. Barcelona, PPU.

Ponce Jiménez, Patricia, (2011) "Pueblos indios y VIH/SIDA: nuevas miradas epidemiológicas, socioculturales y políticas públicas" en Ponce Jiménez, Patricia et al. (coords.) El VIH y los pueblos indígenas. México, Comisión Nacional de los Derechos Humanos.

Ramírez López, Dulce Karol, (2011) "Representaciones sociales de migrantes indígenas en torno al vih-sida: un estudio en tres regiones de Chiapas", en Comisión nacional para el Desarrollo de los pueblos Indígenas (ed.), Informe final de la consulta sobre VIH-Sida y pueblos indígenasenáreasfronterizas. México, CDI. Disponibleen: http://avispasenaccion.files.wordpress.com/2012/02/ informe-cdi-vih-prueba-final.pdf [consultado el 5 de febrero de 2012]

Reartes Peñafiel, Diana Laura, (2010) "Movilidad territorial y construcción de vulnerabilidad frente a ITS/VIH/SIDA entre estudiantes indígenas de Chiapas" en Miradas en Movimiento. Vol. 4, pp. 70-95.

Schein, Edgar, (1992) Organizational culture and leadership. San Francisco, Jossey-Bass.

Scheper-Hughes, Nancy, (1997) La muerte sin llanto. Violencia y vida cotidiana en Brasil. Barcelona, Ariel.

Secretaría de Hacienda (Chiapas, México), (2013) Clasificación municipal y regional. 2013. México, Secretaría de Hacienda. Disponible en: http://www. haciendachiapas.gob.mx/marco-juridico/Estatal/ informacion/Lineamientos/Normativos/2013/ XII-Clas-Mpal-Regional.pdf [consultado el 12 de noviembre de 2013]. 
Sibony, Daniel, (1993) "Institution et racisme", en Wieviorka, Michel (coord.) Racisme et modernité. París, Editions de La Découverte.

Vélez A., Hernán et al., (2005) Fundamentos de medicina. Manual deVIH/SIDA y otras infecciones de transmisión sexual. Bogotá, Corporación para Investigaciones Biológicas.
Wallis, Roy, (1976) The Road to Total Freedom, a Sociological Analysis of Scientology. Londres, Heinemann.

Wallraff, Gunter, (1994 [1987]) Cabeza de turco. Barcelona, Anagrama.

Wierviorka, Michel, (1992) El espacio del racismo. Barcelona, Paidos Ibérica. 